\title{
Comparative total mortality in 25 years in Italian and Greek middle aged rural men
}

\author{
A S Dontas, A Menotti, C Aravanis, P Ioannidis, F Seccareccia
}

\begin{abstract}
Study objective-Mortality over 25 years has been low in the Italian and very low in the Greek cohorts of the Seven Countries Study; factors responsible for this particularity were studied in detail.
\end{abstract}

Participants and settings-1712 Italian and 1215 Greek men, aged 40-59 years, cohorts of the Seven Countries Study, representing over $95 \%$ of the populations in designated rural areas.

Design-Entry (1960-61) data included age, systolic blood pressure (SBP), smoking habits, total serum cholesterol, body mass index (BMI), arm circumference, vital capacity (VC), and forced expiratory volume in $3 / 4$ seconds (FEV); the same data were obtained 10 years later. Multivariate Cox analysis was performed with all causes death in 25 years as end point.

Main results-Italian men had higher entry levels of SBP, arm circumference, BMI, and VC; Greek men had higher cholesterol levels, smoking habits, and FEV. Mortality of Italian men was higher throughout; at 25 years cumulative mortality was $48.3 \%$ and $35.3 \%$ respectively. Coronary heart disease and stroke mortality increased fivefold in Italy and 10fold in Greece between years 10 and 25 . The only risk factor with a significantly higher contribution to mortality in Italian men was cholesterol. However, differences in entry SBP (higher in Italy) and FEV (higher in Greece) accounted for, according to the Lee method, $75 \%$ of the differential mortality between the two populations. At 10 years increases in SBP, cholesterol, BMI, and decreases in smoking habits, VC, FEV, and arm circumference had occurred (deltas). SBP increased more and FEV and VC decreased more in Italy than in Greece. Deltas, fed stepwise in the original model for the prediction of 10 to 25 years mortality, were significant for SBP, smoking, arm circumference, and VC in Greece, and for SBP and VC in Italy.

Conclusion-Higher mortality in Italian men is related to stronger positive effects of entry SBP and weaker negative (protective) effects of FEV; in addition 10 year increases in SBP are higher and 10 year decreases in FEV are larger in Italy. Unaccounted factors, however, related to, for example, differences in the diet, may also have contributed to the differential mortality of these two Mediterranean populations.

(F Epidemiol Community Health 1998;52:638-644)

The Seven Countries Study on cardiovascular diseases has completed 30 years activity and the middle aged populations studied at the onset of the study are presently composed of elderly subjects with exponentially rising death rates. Large differences in mortality from coronary heart disease (CHD) have appeared among the 16 cohorts studied, the Mediterranean cohorts of Italy and Greece presenting markedly lower death rates than cohorts from northern Europe and the US and even cohorts from neighboring inland Mediterranean countries like Croatia and Serbia. ${ }^{12}$

Differences in total mortality have also developed within both of the southern European Mediterranean countries-that is, between the rural cohorts of Crete and Corfu in Greece and those of Crevalcore and Montegiorgio in northern and central Italy. ${ }^{3}$ These differences remain large until today but it is not clear which factors that are primarily responsible for this differential mortality, as with the exception of age and a similar cultural status, the Italian and the Greek cohorts differed at entry in several characteristics.

In a recent analysis the predictors of CHD mortality in 25 years in the Greek cohorts were age, systolic blood pressure (SBP), and smoking. ${ }^{4}$ The proportion of CHD within all causes of death, however, is low in both these Mediterranean populations of the Seven Countries Study. ${ }^{1-3}$ We have therefore examined all cause mortality over 25 years in the four cohorts of these two countries Italy and Greece and studied possible determinants of it, in relation to: (1) risk factors levels at entry, and (2) changes of such factors during the first 10 years of follow up as possible predictors of subsequent 15 year mortality. To the five risk factors commonly studied (age, SBP, cigarette smoking, serum, cholesterol, and body mass index (BMI)), vital capacity (VC), forced expiratory volume (FEV), and arm circumference (as index of muscularity) were added, these factors having previously been shown to be powerful predictors of survival in some cohorts of the Seven Countries Study. ${ }^{56}$

\section{Methods}

The populations studied in this analysis were the two Greek and the two Italian rural cohorts of the Seven Countries Study, enrolled and first examined between 1960 and 1961. The four cohorts were first compared separately but, to increase the cohort size and the number of deaths and thus gain in accuracy, the two 
cohorts from each country were subsequently pooled together. Accordingly, 1215 Greek men aged 40-59 years at entry, representing $96.5 \%$ of men living in preselected villages of Crete and Corfu, and 1712 Italian men of the same age range, representing $98.7 \%$ of men living in the villages of Montegiorgio (central Italy) and Crevalcore (northern Italy) composed the respective populations under comparison in this analysis.

A number of measurements were obtained at entry by international teams of doctors, nurses, and technicians following standard protocols and procedures, reported in detail elsewhere. ${ }^{7-9}$ In the present analysis the following eight factors have been considered: age in years; supine resting SBP of the right arm in $\mathrm{mm} \mathrm{Hg}$ (mean of two consecutive measurements); average number of cigarettes smoked daily, as reported by the subjects; total serum cholesterol in $\mathrm{mg} / \mathrm{dl}$ measured in a casual blood sample by the method of Abell-Kendall, modified by Anderson and Keys, ${ }^{10}$; BMI in kg of weight divided by $\mathrm{m}^{2}$ of height; arm circumference in $\mathrm{mm}$, measured at midpoint of the right arm and mathematically cleaned for the contribution of skin and subcutaneous fat as estimated by the tricipital skinfold; vital capacity in $\mathrm{dl} /$ height in metres; FEV in $3 / 4$ seconds in $\mathrm{dl} /$ height in metres.

The same measurements with the same techniques were also obtained after five and 10 years, when the participation among the survivors was $96 \%$ and $87 \%$ in Greece and $95 \%$ and $88 \%$ in Italy.

Collection of data on mortality and causes of death was complete for all men for the subsequent 25 years, through periodic site visits ascertaining the fatal events and their causes obtained from the local register reviews of clinical records and interviewing relatives, thus enabling a central reviewer (AM) to reach a final diagnosis of cause of death following standard criteria, using the 8th Revision of the WHO-ICD. In the later years of follow up occasional deaths occurring in inaccessible areas in Greece were recorded but the accuracy of diagnosis could not always be checked. Death rates were age standarised, using as reference population the quinquennial age distribution of the pool of all the Seven Countries cohorts.

Risk factors have been compared within pairs of cohorts of single countries and between countries using national pools.
Multivariate analysis was performed for each country using the proportional hazards Cox model with all causes death as end point and the above eight risk factors as predictors.

Subjects with missing information on risk factors on either survey were excluded. Dummy variables were introduced in all occasions to adjust coefficients for between cohort differences not explained by risk factors, as mortality was different between cohorts in the same country. In both countries the cohort with lower mortality rate was taken as reference (Crete in Greece and Montegiorgio in Italy). The coefficients of dummy variables indicate the extent of the extra-risk of the cohort with higher mortality compared with the cohort with lower mortality, not explained by the available factors.

Multivariate analysis was also performed by combining data from both countries predicting 25 years mortality as a function of baseline risk factors levels with interaction terms of risk factors/country (inter-factor) and dummy variable for country (Greece). This allowed the determination of whether the effect of any factor was significantly different between the two countries.

Some models were solved excluding the first 10 years mortality, and taking as end point deaths that occurred between years 10 to 25 and computing the models by using the baseline measurements (year 0 ) and the same measurements plus changes occurring in 10 years, the latter as possible additional predictors of the end points. These changes, called deltas, were obtained from the difference in measurements taken at years 10 and 0 .

The number of men treated in this way was smaller than the number of those examined at year 10 because respiratory measurements were systematically used in the analysis; thus 82 Greek men and 126 Italian men at entry and 43 Greek men and 76 Italian men at year 10 with technically poor respiratory records were excluded.

Finally, the part of the difference in mortality between the Greek and the Italian men that could be attributed to differences in the risk factors levels was estimated by the method of Lee, ${ }^{11}$ which has already been used in some analyses of the Seven Countries Study. ${ }^{12}$

Specifically, if R0 and R1 are the observed death rates in the two countries, and R'0 and $\mathrm{R}$ '1 are the corresponding rates when these are adjusted for the influence of certain covariates

Table 1 Mean entry values of risk factors in the four Italian and Greek populations

\begin{tabular}{|c|c|c|c|c|c|c|c|c|c|c|c|c|}
\hline & \multicolumn{6}{|l|}{ Italy } & \multicolumn{6}{|l|}{ Greece } \\
\hline & \multicolumn{2}{|c|}{$\begin{array}{l}\text { Montegiorgio } \\
(n=681)\end{array}$} & \multicolumn{2}{|c|}{$\begin{array}{l}\text { Crevalcore } \\
(n=905)\end{array}$} & \multicolumn{2}{|c|}{$\begin{array}{l}\text { Total } \\
(n=1586)\end{array}$} & \multicolumn{2}{|c|}{$\begin{array}{l}\text { Crete } \\
(n=624)\end{array}$} & \multicolumn{2}{|c|}{$\begin{array}{l}\text { Corfu } \\
(n=509)\end{array}$} & \multicolumn{2}{|c|}{$\begin{array}{l}\text { Total } \\
(n=1133)\end{array}$} \\
\hline & Mean & $S D$ & Mean & $S D$ & Mean & $S D$ & Mean & $S D$ & Mean & $S D$ & Mean & $S D$ \\
\hline Age (y) & $49.4^{\star}$ & 4.9 & 49.9 & 5.1 & 49.7 & 5.1 & 49.3 & 5.5 & 49.7 & 5.7 & 49.5 & 5.6 \\
\hline Systolic blood pressure (mm Hg) & $137.3^{\star}$ & 18.1 & 147.9 & 21.7 & $143.3^{\star}$ & 20.9 & 136.8 & 19.9 & 134.8 & 20.9 & 135.9 & 20.4 \\
\hline Serum cholesterol $(\mathrm{mg} / \mathrm{dl})$ & 201.7 & 39.3 & 201.6 & 42.6 & $201.7^{\star}$ & 41.2 & 206.2 & 41.1 & 204.5 & 46.0 & 205.4 & 43.4 \\
\hline Cigarettes (n/day) & $7.4^{\star}$ & 9.0 & 9.9 & 10.4 & $8.8^{\star}$ & 9.9 & 11.6 & 13.2 & 11.1 & 10.7 & 11.4 & 12.2 \\
\hline Arm circumference $(\mathrm{cm})$ & $27.3^{\star}$ & 2.2 & 26.7 & 2.4 & $26.9^{\star}$ & 2.4 & $26.8^{\star}$ & 2.2 & 25.2 & 2.1 & 26.1 & 2.3 \\
\hline Body mass index (units) & $24.4^{\star}$ & 3.6 & 25.8 & 3.6 & $25.2^{\star}$ & 3.7 & $22.8^{\star}$ & 3.0 & 23.3 & 3.5 & 23.1 & 3.3 \\
\hline Vital capacity $(\mathrm{dl} / \mathrm{m})$ & 23.1 & 3.4 & 23.0 & 3.7 & $23.0^{\star}$ & 3.6 & $22.8^{\star}$ & 3.2 & 22.3 & 3.6 & 22.6 & 3.4 \\
\hline Forced expiratory volume $(\mathrm{d} 1 / \mathrm{m})$ & 13.8 & 3.2 & 14.1 & 3.2 & $13.9^{\star}$ & 3.2 & $15.3^{\star}$ & 3.0 & 15.7 & 3.2 & 15.5 & 3.1 \\
\hline
\end{tabular}

${ }^{\star} t$ Test Montegiorgio $v$ Crevalcore; Crete $v$ Corfu $\mathrm{p}<0.05$ or less; Italy $v$ Greece $\mathrm{p}<0.05$ or less. 
Table 2 Mean values of risk factors in men alive at 10 years in the four Italian and Greek populations

\begin{tabular}{|c|c|c|c|c|c|c|c|c|c|c|c|c|}
\hline & \multicolumn{6}{|l|}{ Italy } & \multicolumn{6}{|l|}{ Greece } \\
\hline & \multicolumn{2}{|c|}{$\begin{array}{l}\text { Montegiorgio } \\
(n=354)\end{array}$} & \multicolumn{2}{|c|}{$\begin{array}{l}\text { Crevalcore } \\
(n=597)\end{array}$} & \multicolumn{2}{|c|}{$\begin{array}{l}\text { Total } \\
(n=951)\end{array}$} & \multicolumn{2}{|c|}{$\begin{array}{l}\text { Crete } \\
(n=488)\end{array}$} & \multicolumn{2}{|c|}{$\begin{array}{l}\text { Corfu } \\
(n=287)\end{array}$} & \multicolumn{2}{|c|}{$\begin{array}{l}\text { Total } \\
(n=775)\end{array}$} \\
\hline & Mean & $S D$ & Mean & $S D$ & Mean & $S D$ & Mean & $S D$ & Mean & $S D$ & Mean & $S D$ \\
\hline Age (y) & 58.5 & 4.6 & 59.1 & 4.8 & 58.9 & 4.7 & $58.8^{\star}$ & 5.4 & 59.8 & 5.7 & 59.2 & 5.5 \\
\hline Systolic blood pressure $(\mathrm{mm} \mathrm{Hg})$ & $149.1^{\star}$ & 21.9 & 154.7 & 22.6 & $152.6^{\star}$ & 22.5 & $137.0^{\star}$ & 23.6 & 149.4 & 19.8 & 141.4 & 23.1 \\
\hline Serum cholesterol $(\mathrm{mg} / \mathrm{d})$ & $217.3^{\star}$ & 47.2 & 225.3 & 46.1 & $222.3^{\star}$ & 46.6 & $232.9^{\star}$ & 43.3 & 221.9 & 48.1 & 229.0 & 45.3 \\
\hline Cigarettes (n/day) & $5.9^{\star}$ & 7.5 & 7.4 & 9.3 & $6.9^{\star}$ & 8.7 & 11.2 & 12.7 & 10.2 & 10.4 & 10.8 & 11.9 \\
\hline Arm circumference $(\mathrm{cm})$ & 26.3 * & 2.2 & 27.1 & 2.4 & $26.8^{\star}$ & 2.4 & $24.7^{\star}$ & 2.0 & 24.4 & 2.1 & 24.6 & 2.1 \\
\hline Body mass index (units) & $25.3^{\star}$ & 3.8 & 26.6 & 3.8 & $26.1^{\star}$ & 3.8 & 24.2 & 3.4 & 24.4 & 3.8 & 24.3 & 3.6 \\
\hline Vital capacity $(\mathrm{d} 1 / \mathrm{m})$ & $19.8^{\star}$ & 2.6 & 20.5 & 2.6 & 20.2 & 2.6 & $21.2^{\star}$ & 3.5 & 18.7 & 3.7 & 20.3 & 3.8 \\
\hline Forced expiratory volume $(\mathrm{dl} / \mathrm{m})$ & $11.7^{\star}$ & 1.7 & 12.3 & 1.8 & $12.1^{\star}$ & 1.8 & $14.8^{\star}$ & 3.7 & 12.2 & 3.1 & 13.9 & 3.7 \\
\hline
\end{tabular}

${ }^{\star} t$ Test Montegiorgio $v$ Crevalcore; Crete $v$ Corfu $\mathrm{p}<0.05$ or less; Italy $v$ Greece $\mathrm{p}<0.05$ or less.
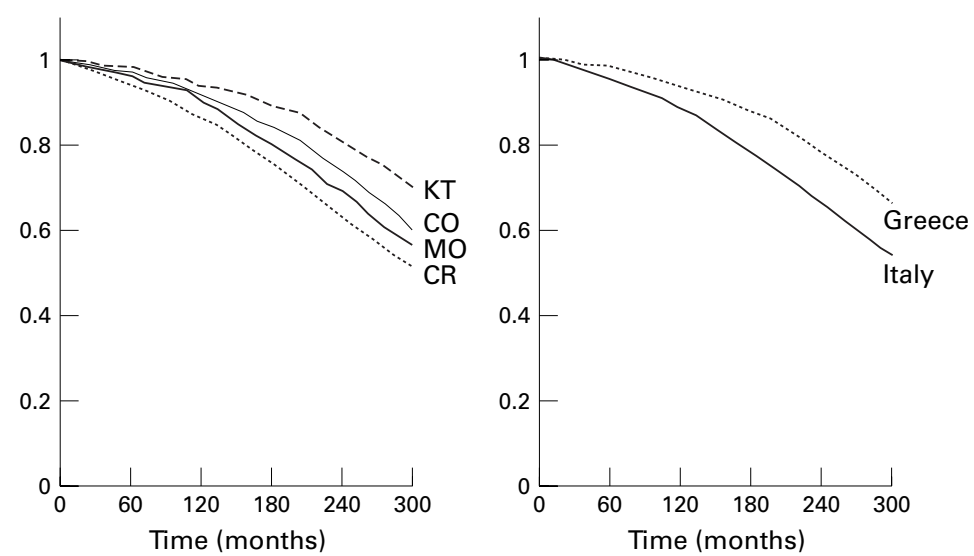

Figure 1 Cumulative survival curves for the four cohorts of the study for 300 months (left); on the right side the two cohorts of each country have been combined to illustrate the survival of the two national groups. $K T=$ Crete, $C O=$ Corfu; $M O=$ Montegiorgio; $C R=$ Crevalcore.

then the ratio $\mathrm{q}=\left(\mathrm{R}^{\prime} 0-\mathrm{R}^{\prime} 1 / \mathrm{R} 0-\mathrm{R} 1\right)$ gives the proportion of differential risk between the two populations not attributable to differences in the risk factors levels and $\mathrm{p}=1-\mathrm{q}$ is the proportion of differential risk attributable to differences in the risk factors levels.

\section{Results}

BASELINE CHARACTERISTICS AND 10 YEAR CHANGES

Table 1 shows the entry mean values of risk factors and $t$ tests between the four cohorts.

In Italy, mean levels of age, SBP, cigarette smoking, and BMI were significantly greater in Crevalcore, whereas arm circumference was greater in Montegiorgio.

In Greece, arm circumference and VC were greater in Crete, whereas FEV and BMI were greater in Corfu.

In comparing the two countries through their pools of cohorts, higher mean levels of SBP, arm circumference, BMI, and VC were found in Italy, whereas higher levels of serum cholesterol, cigarette smoking, and FEV were found in Greece. Thus, the two countries differed significantly at entry in all factors but age.

At the 10 year re-survey, in Italy all factors except age, were again significantly higher in Crevalcore than in Montegiorgio. In Greece, age and SBP were higher in Corfu than in Crete, whereas serum cholesterol, arm circumference, VC, and FEV were higher in Crete (table 2). When comparing the pools of the two countries, the same significant differences were found as at the entry examination, except for VC, which was not different between the two countries.

In summary, large increases occurred over 10 years in both countries in SBP and serum cholesterol, an increase in BMI and decreases in cigarette consumption, arm circumference, $\mathrm{VC}$, and FEV.

DEATH RATES IN ITALIAN AND GREEK COHORTS Table 3 shows the cumulative quinquennial death rates in 25 years in the four individual cohorts and the two pooled national groups. In Italy, rates in Crevalcore are always greater than in Montegiorgio and on two occasions they are significantly different. In Greece, death rates in Corfu are always higher than in Crete and in three occasions they are significantly different.

In both countries, therefore, there was an area with a consistently higher death rate than the other one. When comparing the pooled national groups, the Italians had always higher death rates than the Greeks and their difference at each quinquennial dead-line was statistically significant. Moreover, death rates in the low mortality area in Italy (Montegiorgio) always exceeded the rates in the Greek high mortality area (Corfu).

Figure 1 contains survival curves for the four cohorts separately and for the two countries for

Table 3 Age adjusted 25 year death rates (per 1000) and their 95\% CI (in parentheses) from all causes in four cohorts and two countries

\begin{tabular}{|c|c|c|c|c|c|c|c|c|c|}
\hline & \multicolumn{3}{|l|}{ Italy } & \multicolumn{3}{|l|}{ Greece } & \multirow[b]{2}{*}{$\begin{array}{l}\text { Italy } \\
(n=1712)\end{array}$} & \multirow[b]{2}{*}{$\begin{array}{l}\text { Greece } \\
(n=1215)\end{array}$} & \multirow[b]{2}{*}{$\begin{array}{l}\text { Ratio } \\
\text { Italy/Greece }\end{array}$} \\
\hline & $\begin{array}{l}\text { Crevalcore } \\
(n=993)\end{array}$ & $\begin{array}{l}\text { Montegiorgio } \\
(n=719)\end{array}$ & $\begin{array}{l}\text { Crev/Mont } \\
\text { Ratio }\end{array}$ & $\begin{array}{l}\text { Corfu } \\
(n=529)\end{array}$ & $\begin{array}{l}\text { Crete } \\
(n=686)\end{array}$ & $\begin{array}{l}\text { Corfu/Crete } \\
\text { Ratio }\end{array}$ & & & \\
\hline Year 5 & $62(47,77)$ & $41(26,56)$ & 1.51 & $29(15,43)$ & $17(7,27)$ & 1.71 & $53^{\star}(42,64)$ & $22(14,30)$ & 2.41 \\
\hline Year 10 & $140^{\star}(118,162)$ & $106(83,128)$ & 1.32 & $83(59,106)$ & $66(47,85)$ & 1.26 & $126^{\star}(110,142)$ & $73(58,88)$ & 1.73 \\
\hline Year 15 & $248(221,275)$ & $215(185,245)$ & 1.15 & $157^{\star}(126,188)$ & $114(90,138)$ & 1.38 & $234^{\star}(214,254)$ & $133(114,152)$ & 1.76 \\
\hline Year 20 & $379^{\star}(349,409)$ & $325(291,359)$ & 1.17 & $263^{\star}(225,300)$ & $204(174,234)$ & 1.29 & $356^{\star}(333,379)$ & $230(206,254)$ & 1.55 \\
\hline Year 25 & $498(467,529)$ & $462(426,498)$ & 1.08 & $404 \star(362,446)$ & $314(279,349)$ & 1.29 & $483^{\star}(459,507)$ & $353(326,389)$ & 1.37 \\
\hline
\end{tabular}

${ }^{\star} \mathrm{p}<0.05$ between areas of the same country and between countries. 


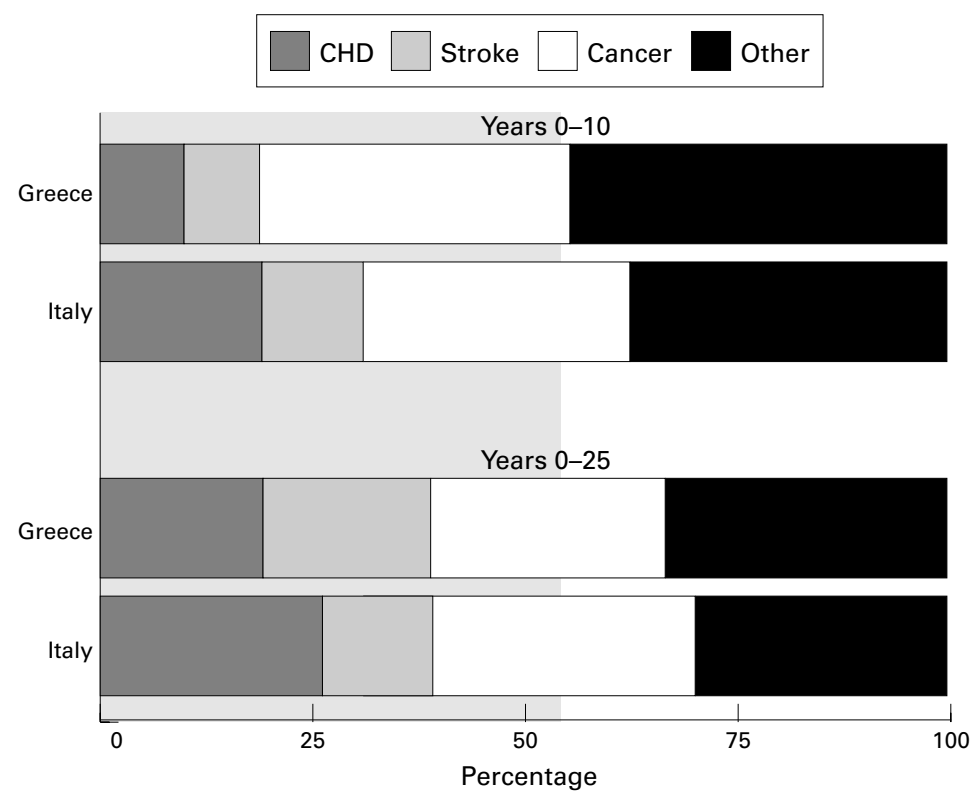

Figure 2 Breakdown of death rates in four causes of death in two periods for the two countries, expressed as proportions of total mortality (fixed at 100 per cent for each country and each period).

the period of 300 months (25 years), the proportion of surviving persons being recorded every six months. The differences in survival become obvious from the 120th month and the negative slopes of the cumulative survival become steeper in both countries until about 200 months, chiefly through an acceleration of the deaths in the Greek cohorts, whose death rates at 15,20, and 25 years equal those of the Italian cohorts five years earlier. After 25 years the Italy to Greece mortality ratio although aproaching unity remains still significantly greater than one (table 3 ).

BREAKDOWN OF ALL CAUSES OF DEATH OVER THE FOLLOW UP PERIOD

Table 4 gives the breakdown of four major causes of death within total mortality for the two countries for the 0 to 10 years and the 0 to 25 years periods. There are differences in specific causes among the four cohorts and the two combined cohorts, the major differences being represented by much higher death rates from $\mathrm{CHD}$, cancer, and other causes in Italy and non-significant higher rates from stroke at 0 to 25 years in Greece (stroke deaths in Italy are higher at 0 to 10 years).

In figure 2 the breakdown of causes of death, as proportions within total mortality, expressed as $100 \%$ in the two populations for two follow up periods - that is, $0-10$ and $0-25$ yearsindicates the changing pattern of causes of death. There is an increase of CHD compared
KEY POINTS

- Twenty five year total mortality was $37 \%$ higher in 1712 middle aged rural Italian men compared with 1215 Greek men. Among eight factors studied at entry to the study only cholesterol had a Cox coefficient significantly higher in Italy; however, entry SBP and FEV (protective) together accounted for $75 \%$ of the mortality difference. Smaller increments of SBP and smaller decrements of FEV over 10 years in Greek men may also have contributed to the mortality differences.

- Among the 16 cohorts of the Seven Countries Study those of Crevalcore and Montegiorgio in Italy, and Crete and Corfu in Greece have had the lowest coronary heart disease and total death rates over 25 years. During this period, age adjusted total mortality of the Italian cohorts $(48.3 \%)$ exceeded significantly that of the Greek cohorts (35.3\%). Cox analysis indicated that coefficients of entry cholesterol were significantly higher in Italy than in Greece; however, $75 \%$ of the higher mortality in Italy was accounted for by the higher entry levels of SBP and lower entry levels of FEV in 3/4 seconds. Normalising these modifiable factors may, therefore, improve life expectancy in middle age.

with "other causes" of death within the increasing mortality from the shorter to the longer follow up period. The larger contribution of CHD deaths in the Italian cohorts is obvious, as is the faster increase of this cause of death in Greece.

\section{MULTIVARIATE ANALYSIS}

Table 5 shows the multivariate analysis of deaths for deaths occurring during the whole 25 year period and the two pooled national groups. Levels of risk factors at entry are used and solutions are given as coefficients of risk factors, their $t$ values and their exponentials. Among the eight risk factors four-that is, age, SBP, cigarette smoking, and FEV (protective), were statistically significant predictors of all cause death in both countries, whereas arm circumference was a protective factor in Italy but not in Greece. The dummy variables suggest that significant unexplained mortality difference does not exist between the two Italian cohorts (Crevalcore and Montegiorgio), whereas significant unexplained difference does exist between the two Greek cohorts, with

Table 4 Death rates per 1000, and their 95\% CI (in parentheses) from years 0 to 10 and 0 to 25 of follow up in the pool of the Italian $(n=1712)$ and the Greek $(n=1215)$ populations

\begin{tabular}{|c|c|c|c|c|c|c|}
\hline & \multicolumn{3}{|l|}{ Years $0-10$} & \multicolumn{3}{|l|}{ Years $0-25$} \\
\hline & Italy & Greece & p Value & Italy & Greece & p Value \\
\hline $\mathrm{CHD}$ & $24(17,32)$ & $7(3,14)$ & 0.0003 & $126(111,143)$ & $76(62,93)$ & 0.0000 \\
\hline Stroke & $15(10,22)$ & $7(3,13)$ & 0.0147 & $62(51,75)$ & $70(56,86)$ & 0.3870 \\
\hline Cancer & $40(31,50)$ & $27(19,38)$ & 0.0352 & $150(133,167)$ & $97(81,115)$ & 0.0134 \\
\hline Other causes & $47(37,58)$ & $32(23,44)$ & 0.0263 & $145(129,163)$ & $119(101,138)$ & 0.0419 \\
\hline All causes & $126(111,143)$ & $74(59,89)$ & 0.0000 & $483(459,507)$ & $353(326,381)$ & 0.0000 \\
\hline
\end{tabular}


Table 5 Cox model analysis with eight covariates at entry and deaths from year 0 to 25 (deaths/denominator)

\begin{tabular}{|c|c|c|c|c|c|c|}
\hline & \multicolumn{3}{|c|}{ Italy (732 of 1586) } & \multicolumn{3}{|c|}{ Greece (393 of 1133) } \\
\hline & Coefficient & SEM & $95 \% C I$ & Coefficient & SEM & $95 \% C I$ \\
\hline Age $(y)$ & $0.0909^{\star}$ & 0.0082 & $0.0748,0.1230$ & $0.0728^{\star}$ & 0.0108 & $0.0516,0.0940$ \\
\hline Systolic blood presure $(\mathrm{mm} \mathrm{Hg})$ & $0.0146^{\star}$ & 0.0018 & $0.0111,0.0181$ & $0.0144^{\star}$ & 0.0025 & $0.0095,0.0193$ \\
\hline Serum cholesterol $(\mathrm{mg} / \mathrm{dl})$ & $0.0030^{\star}$ & 0.0009 & $0.0012,0.0048$ & -0.0021 & 0.0013 & $-0.0046,0.0004$ \\
\hline Cigarettes ( $\mathrm{n} /$ day) & $0.0173^{\star}$ & 0.0037 & $0.0100,0.0246$ & $0.0107^{\star}$ & 0.0042 & $0.0025,0.0189$ \\
\hline Arm circumference $(\mathrm{cm})$ & $-0.0062^{\star}$ & 0.0021 & $-0.0103,-0.0021$ & -0.0022 & 0.0035 & $-0.0091,0.0047$ \\
\hline Body mass index (units) & 0.0019 & 0.0136 & $-0.0248,0.0286$ & -0.0137 & 0.0228 & $-0.0584,0.0310$ \\
\hline Vital capacity $(\mathrm{dl} / \mathrm{m})$ & -0.0241 & 0.0136 & $-0.0510,0.0026$ & 0.0049 & 0.0233 & $-0.0408,0.0506$ \\
\hline \multicolumn{7}{|l|}{ Forced expiratory volume } \\
\hline$(\mathrm{d} 1 / \mathrm{m})$ & $-0.0674^{\star}$ & 0.0154 & $-0.0976,-0.0372$ & $-0.0725^{\star}$ & 0.0256 & $-0.1227,-0.0223$ \\
\hline Dummy Crevalcore & -0.1019 & 0.0835 & $-0.2656,0.0618$ & - & - & - \\
\hline Dummy Corfu & - & - & - & $0.3422^{\star}$ & 0.1213 & $0.1044,0.5800$ \\
\hline
\end{tabular}

${ }^{\star} \mathrm{p}<0.05$ of coefficients within each country. The coefficient for serum cholesterol is significantly different between the two countries.

lower mortality in Crete and higher mortality in Corfu. Coefficients of covariates were generally larger in Italy, but only those of serum cholesterol were significantly different between the two countries, the coefficient of serum cholesterol in Greece having a non-significant negative sign.

From the data of table 5 the relative risks for arbitary differences in the levels of risk factors can be computed. For example, for a difference of SBP of $20 \mathrm{~mm} \mathrm{Hg}$ the relative risk is 1.34 in Italy (95\% CI 1.25 and 1.44 ) and 1.33 in Greece (95\% CI 1.21 and 1.47). For a difference of $3 \mathrm{dl} / \mathrm{m}$ in FEV the relative risk is 0.82 in Italy and 0.80 in Greece $(95 \%$ CI in Italy 0.75 and 0.89 ; in Greece 0.69 and 0.93 ).

Table 6 gives the solution of the Cox model with interactions. All baseline risk factors produce significant coefficients except BMI and VC, whose coefficient is not far from significance. The dummy variable for Greece is not significant. Interaction terms are all statistically not significant except that for serum cholesterol, with a negative value. This means that serum cholesterol is directly related to mortality but only in the country with lower cholesterol concentrations (Italy). The fact that the coefficient of serum cholesterol alone is significant (positive) is because of the strong relation in Italy.

EFFECTS OF RISK FACTOR CHANGES (DELTAS) This analysis was done for fatal events occurring between years 10 and 25 of follow up, still using the entry levels of risk factors,

Table 6 Solution of the Cox model including both Greek and Italian cohorts, predicting 25 year all cause mortality as a function of baseline risk factors levels, with interaction terms of risk factors/country (inter-factor), and dummy variable for country (Italy is reference)

\begin{tabular}{llll}
\hline Risk factor & Coefficient & SEM & $95 \% C I$ \\
\hline Age & $0.0917^{\star}$ & 0.0082 & $0.0756,0.1078$ \\
Cigarettes (n/day) & $0.0167^{\star}$ & 0.0037 & $0.0094,0.0239$ \\
Systolic blood pressure & $0.0143^{\star}$ & 0.0018 & $0.0108,0.0178$ \\
Serum cholesterol & $0.0031^{\star}$ & 0.0009 & $0.0013,0.0049$ \\
Body mass index & -0.0033 & 0.0134 & $-0.0296,0.0230$ \\
Arm circumference & $-0.0055^{\star}$ & 0.0020 & $-0.0094,-0.0016$ \\
Vital capacity & -0.0258 & 0.0135 & $-0.0523,0.0007$ \\
Forced expiratory volume & $-0.0686^{\star}$ & 0.0153 & $-0.0986,-0.0386$ \\
Greece dummy & 1.3355 & 1.2054 & $-1.0271,3.6981$ \\
Inter-age & -0.0201 & 0.0135 & $-0.0466,0.0064$ \\
Inter-cigarettes & -0.0061 & 0.0056 & $-0.0171,0.0049$ \\
Inter-systolic BP & -0.0005 & 0.0031 & $-0.0035,0.0025$ \\
Inter-cholesterol & $-0.0053^{\star}$ & 0.0016 & $-0.0084,-0.0022$ \\
Inter-body mass index & 0.0144 & 0.0245 & $-0.0336,0.0624$ \\
Inter-arm circumference & -0.0015 & 0.0036 & $-0.0086,0.0056$ \\
Inter-vital capacity & 0.0217 & 0.0268 & $-0.0308,0.0742$ \\
Inter-forced expiratory volume & 0.0099 & 0.0296 & $-0.0481,0.0679$ \\
\hline
\end{tabular}

$\mathrm{p}<0.05$ for coefficients. and adding in a stepwise manner the $0-10$ year changes of the same factors as additional covariates. The upper part of table 7 suggests that some baseline risk factors are predictive of delayed, 10 to 25 year mortality. These are age, $\mathrm{SBP}$, and cigarette smoking in both countries, and VC and FEV (protective in Italy). In addition, deltas offered in a stepwise manner are also predictive of delayed events. In particular, increases in SBP in both countries and cigarette smoking (in Greece) are predictive of increased delayed mortality. At the same time decreases of arm circumference in Greece and of $\mathrm{VC}$ in both countries less than the mean decrements within each country are also predictive of reduced delayed mortality. In Italy the coefficient of delta in cigarette smoking was not far from significant, but is reported because the critical level in the stepwise procedure was set at $\mathrm{p}=0.10$.

Separately, a model for prediction of delayed mortality was solved with inclusion of baseline factors only (not reported herein). The coefficients of risk factors in both countries had the same signs, similar levels and $t$ value as those reported in the model including also the risk factor changes.

These findings indicate that beyond and above the predictive power of baseline measurements, increases over the mean at baseline of SBP and of cigarette smoking during 10 years are associated with an excess total mortality in both countries, whereas decreases of VC (and arm circumference in Greece) less than the mean reductions of these values within each country are associated with a reduced mortality.

EXPLANATION OF DEATH RATES BY THE RISK FACTORS AT ENTRY

The computation of the Lee procedure, not reported here in detail, makes covariance adjustments on multivariate solutions to identify the proportion of differential mortality that can be attributed to different levels of risk factors. Using the baseline levels of risk factors and 25 year death rates the difference in mean SBP (higher in Italy) explains, alone, 34\% of the differential mortality between Italy and Greece. When FEV (higher in Greece) is added to the system, the proportion explained becomes $75 \%$. All other factors did not help in explaining the residual difference in all cause mortality. However, this means that only $25 \%$ 
Table 7 Cox model analysis, step wise procedure, with eight baseline factors forced into the model and changes (10y-0y $=$ delta) free to enter. Deaths occurring between year 10 and 25 of follow up. (deaths/denominator)

\begin{tabular}{|c|c|c|c|c|c|c|}
\hline & \multicolumn{3}{|c|}{ Italy (324 of 951) } & \multicolumn{3}{|c|}{ Greece (205 of 775) } \\
\hline & Coefficient & SEM & $95 \% C I$ & Coefficient & SEM & $95 \% C I$ \\
\hline Age $(y)$ & $0.0975^{\star}$ & 0.0128 & $0.0724,0.1226$ & $0.0615^{\star}$ & 0.0158 & $0.0304,0.0926$ \\
\hline Systolic blood presure $(\mathrm{mm} \mathrm{Hg})$ & $0.0154^{\star}$ & 0.0032 & $0.0092,0.0216$ & $0.0185^{\star}$ & 0.0038 & $0.0110,0.0260$ \\
\hline Serum cholesterol $(\mathrm{mg} / \mathrm{dl})$ & 0.0021 & 0.0014 & $-0.0006,0.0048$ & -0.0023 & 0.0018 & $-0.0058,0.0012$ \\
\hline Cigarettes (n/day) & $0.0238^{\star}$ & 0.0066 & $0.0108,0.0368$ & $0.0215^{\star}$ & 0.0061 & $0.0095,0.0335$ \\
\hline Arm circumference $(\mathrm{cm})$ & -0.0001 & 0.0050 & $-0.0099,0.0097$ & -0.0066 & 0.0054 & $-0.0172,0.0040$ \\
\hline Body mass index (units) & -0.0042 & 0.0221 & $-0.0475,0.0391$ & 0.0003 & 0.0300 & $-0.0585,0.0591$ \\
\hline Vital capacity $(\mathrm{dl} / \mathrm{m})$ & $-0.0527^{\star}$ & 0.0253 & $-0.0124,-0.0300$ & -0.0126 & 0.0340 & $-0.0793,0.0541$ \\
\hline \multicolumn{7}{|l|}{ Forced expiratory volume } \\
\hline$(\mathrm{d} l / \mathrm{m})$ & $-0.0489^{\star}$ & 0.0237 & $-0.0954,-0.0024$ & -0.0286 & 0.0371 & $-0.1014,0.0442$ \\
\hline Dummy Crevalcore & 0.0477 & 0.1363 & $-0.2194,0.3148$ & - & - & - \\
\hline Dummy Corfu & - & - & - & 0.1117 & 0.1862 & $-0.2532,0.4766$ \\
\hline Delta-systolic blood pressure & $0.0070^{\star}$ & 0.0033 & $0.0006,0.0134$ & $0.0104^{\star}$ & 0.0039 & $0.0026,0.0181$ \\
\hline Delta-cigarettes & 0.0168 & 0.0092 & $-0.0013,0.0349$ & $0.0195^{\star}$ & 0.0087 & $0.0024,0.0366$ \\
\hline Delta-arm circumference & - & - & - & $-0.0116^{\star}$ & 0.0049 & $-0.0212,-0.0020$ \\
\hline Delta-vital capacity & $-0.1468^{\star}$ & 0.0354 & $-0.2161,-0.0775$ & $-0.0645^{\star}$ & 0.0304 & $-0.1241,-0.0049$ \\
\hline
\end{tabular}

${ }^{\star} \mathrm{p}<0.05$ of coefficients within each country.

of death rate differences between the two countries cannot be accounted for by the differences in the eight risk factors studied here.

\section{Discussion}

This analysis has chosen as end point "all cause" mortality in two of the Seven Countries Study rural populations having low rates of total mortality in Europe. ${ }^{29}$ This target was chosen because of the frequently inaccurate data on exact causes of death in older subjects. For example, above the age of 65 years CHD may be mimicked by other diseases, multiple rather than single causes may be present and interact, and atypical manifestations of $\mathrm{CHD}$ may be misclassified under a variety of diagnoses. Finally, prediction and possibly reduction of all cause mortality, thus prolongation of survival, is a more important objective than identification of the factors responsible for particular causes of mortality, even CHD, which accounts for only $22 \%$ and $26 \%$ respectively of the 25 year total mortality in the Greek and Italian populations studied (table 4).

The findings indicate that the cumulative deaths in the combined two Italian cohorts compared with those of the combined two Greek cohorts are significantly higher at each quinquennium; at 25 years these are caused by higher death rates from coronary heart disease $(166 \%)$, cancer $(155 \%)$, and "other causes" $(122 \%)$ (table 4$)$. As evident from table 3 and figure 1 despite the delayed acceleration in mortality of the Greek cohorts the difference in mortality between the two countries remained highly significant at 25 years $(+37 \%)$, with the Italian population having reached a cumulative death rate of almost $50 \%$.

With regard to the eight factors examined it was shown that although the coefficients of age, SBP, smoking, and FEV in the Cox models differed from zero in both countries, only that of serum cholesterol was significantly higher in Italy (table 5 ). On the other hand, $75 \%$ of the difference in mortality at 25 years between the two countries could be accounted for by the difference in two factors at entry, namely SBP and FEV. In this case despite similar and nonsignificantly different coefficients in the multivariate models, the difference between the two countries involved higher mean levels of SBP in Italy and higher mean levels of FEV in Greece, both unfavourable to Italy.

SBP, a potentially modifiable risk factor, has about equal coefficients in both countries but confidence intervals are wider in Greece (table 5 ) and the 10 year increase much less than in Italy $(5.5 \mathrm{mmHg} v 9.3 \mathrm{~mm} \mathrm{Hg}$ ).

The finding of negative coefficients for cholesterol and BMI in the Cox models for Greece and positive coefficients for Italy is rather puzzling, in view of the general, positive, and linear relation of cholesterol and inverse of BMI to CHD mortality in short and longer follow ups of the Seven Countries. ${ }^{2}{ }^{9}$ This paradox could be because of a parabolic, inverse $\mathrm{J}$ shaped effect of cholesterol-that is, increased mortality in low values in the Greek cohorts; this possibility has been tested herein by adding a quadratic term (squared) for cholesterol and BMI in the Cox models of the two populations. The results, not reported here, indicate that a parabolic effect of cholesterol on mortality does exist in Greece but not in Italy; conversely, a parabolic effect for BMI exists in Italy but not in Greece.

The respiratory measure of FEV at entry proved to be an important factor of survival in both countries (table 5). When the changes between 0 and 10 years are included in the model, in Italy entry FEV and VC and deltas of VC all exert a significant protective effect at 10-25 years whereas in Greece only deltas in VC exert such a protective action at this late period (table 7). Lesser decrements of mean values of $\mathrm{VC}$ and $\mathrm{FEV}$ occurred over 10 years in Greece $(2.3 \mathrm{dl} / \mathrm{m}$ and $1.6 \mathrm{dl} / \mathrm{m})$ compared with Italy $(2.8 \mathrm{dl} / \mathrm{m}$ and $1.8 \mathrm{dl} / \mathrm{m})$.

Additional factors must have been present; diet has not been discussed in this analysis because direct measurements of nutrient intakes have been available for only small subsamples of each population. However, the proportion of total fat has been reported as $36 \%$ and $33 \%$ in Crete and Corfu compared with $27 \%$ and $25 \%$ in Crevalcore and Montegiorgio; monounsaturated fatty acids $26 \%$ and $18 \%$ in Greece compared with $11 \%$ and $12 \%$ in Italy; protein $11 \%$ in Greece and $13 \%$ and $11 \%$ in Italy. ${ }^{15}$ Data indicate that among elderly Greeks those consuming a Mediterranean diet 
meeting currently accepted health criteria have a significant reduction in overall mortality. ${ }^{16}$ Finally, smoking has far less of a negative impact on VC and FEV in the Cretan population herein than in other cohorts of the Seven Countries. ${ }^{6} 17$

In conclusion, this analysis has shown that 25 year all cause mortality is consistently higher in rural Italy than in rural Greece. Of eight factors studied at entry the higher levels of SBP in Italy and the higher levels of FEV (protective) in Greece accounted for $75 \%$ of this difference. Greek men are probably further protected by smaller rises in SBP and smaller decrements in VC and FEV levels over a 10 year study period, and other factors possibly related to the diet.

The authors gratefully acknowledge the help and support of Prof Ancel Keys for the initiation and follow up of this study for more than 25 years.

Funding:the study was supported by grants HE 04697, HE 6090 , and HE 00278 from the National Heart, Lung and Blood Institute, the Embiricos Foundation, SEVITEL, Bayer Hellas AG, and Nestle-Loumidis SA, Greece.

Conflicts of interest: none.

1 Menotti A, Keys A, Blackburn H, et al. Comparison of multivariate predictive power of major risk factors for coronary heart disease in different countries. Results from eight nations of the Seven Countries Study, 25-year follow-up. $\mathcal{F}$ nations of the Seven Countries
Cardiovasc Risk 1996;3:69-75.

2 Verschuren WMM, Jacobs DR, Bloemberg BPM, et al. $\mathrm{H}$. Serum total cholesterol and long-term coronary heart disease mortality in different cultures. Twenty-five-year ease mortality in different cultures. Twenty-five-year
follow-up of the Seven Countries Study. FAMA 1995;274: follow-
3 Menotti A, Keys A, Kromhout D, et al. Inter-cohort differences in coronary heart disease mortality in the 25 -year follow-up of the Seven Countries Study. Eur 7 Epidemiol 1993;9: 527-36

4 Dontas AS, Menotti A, Aravanis C, et al. Long-term prediction of coronary heart disease mortality in two rural Greek populations. Eur Heart F 1993;14:1153-7.

5 Menotti A, Mariotti S, Seccareccia F, et al. Determinants of all causes of death in Italian middle-aged men followed-up for 25 years. $\mathcal{F}$ Epidemiol Community Health 1987;41:24350 .

6 Keys A. Seven Countries. A multivariate analysis of death and coronary heart disease. Cambridge, MA: Harvard University Press, 1980: 381.

7 Keys A, Aravanis C, Blackburn H, et al. Probability of middle aged men developing coronary heart disease in five years. Circulation 1972;45:815-28.

8 Keys A, Menotti A, Aravanis C, et al. The Seven Countries Study: 2289 deaths in 15 years. Prev Med 1984;13:141-54.

9 Menotti A, Keys A, Aravanis C, et al. Seven Countries Study. First 20 year mortality data in 12 cohorts of six Countries. Ann Med 1989;21:175-9.

10 Anderson JT, Keys A. Serum cholesterol in serum and lipoprotein fractions: its measurement and stability. Clin Chem $1956 ; 2: 145-59$.

11 Lee J. Covariance adjustment of rates based on the multiple logistic regression model. F Chron Dis 1981;34:415-26.

12 Mariotti S, Capocaccia R, Farchi G, et al. Differences in the incidence of coronary heart disease between North and South European cohorts of the Seven Countries Study. Eur Heart F 1982;3:481-7.

13 Menotti A, Keys A, Blackburn $\mathrm{H}$, et al. Blood pressure changes as predictors of future mortality in the Seven Countries Study. F Hum Hypertens 1991;5:137-44.

14 Menotti A, Descovich GC, Lanti M, et al. Indexes of obesity and all-cause mortality in Italian epidemiological data. Prev Med 1993;22:293-303.

15 Keys A, Menotti A, Karvonen MJ, et al. The diet and 15 -year death rate in the Seven Countries Study. Am $\mathcal{F}$ Epidemiol 1986;124:903-15.

16 Trichopoulou A, Kouris-Blazos A, Wahlqvist ML, et al. Diet and overall survival in elderly people. BMF 1995;311: 1457-60.

17 Dontas AS, Jacobs DR, Corcondilas A, et al. Longitudinal versus cross-sectional vital capacity changes and affecting factors. F Gerontol 1984;39:430-8. 